\title{
Os limites do modelo de cidade turística de Cabo Frio, RJ: quando a luz acende e apaga.
}

Limitations of the tourist town in Cabo Frio, RJ: when the light flickers.

Los límites del modelo de ciudad turística de Cabo Frío, RJ: cuando la luz enciende y apaga.

Les limites du modèle de la ville de Cabo Frio (état de Rio de Janeiro) vouée au tourisme: quand la lumière s'allume et séteint.

\section{Felipe de Souza Ramão}

\section{(epenEdition}

Journals

\section{Edição electrónica}

URL: http://journals.openedition.org/espacoeconomia/4449

DOI: $10.4000 /$ espacoeconomia.4449

ISSN: $2317-7837$

\section{Editora}

Núcleo de Pesquisa Espaço \& Economia

\section{Refêrencia eletrónica}

Felipe de Souza Ramão, « Os limites do modelo de cidade turística de Cabo Frio, RJ: quando a luz acende e apaga. », Espaço e Economia [Online], 13 | 2018, posto online no dia 05 janeiro 2019, consultado o 20 abril 2019. URL : http://journals.openedition.org/espacoeconomia/4449 ; DOI : 10.4000/espacoeconomia.4449

Este documento foi criado de forma automática no dia 20 Abril 2019. 


\title{
Os limites do modelo de cidade turística e estadia temporária de Cabo Frio, RJ: quando a luz acende e apaga.
}

\author{
Limitations of the tourist town and lodging model in Cabo Frio, RJ: when the \\ light flickers. \\ Los límites del modelo de ciudad turística e alojamiento temporal de Cabo Frío, \\ RJ: cuando la luz enciende y apaga. \\ Les limites du modèle de la ville de Cabo Frio (état de Rio de Janeiro) vouée au \\ tourisme et aux séjours temporaires : quand la lumière s'allume et séteint.
}

Felipe de Souza Ramão

\section{Introdução}

1 O turismo e a estadia temporária são duas atividades econômicas importantes em muitas cidades de todo o mundo, pelo menos desde o século $\mathrm{XX}$, quando se consolidam e se expandem em um ritmo significativo, inseridas em um contexto que envolve transformações econômicas, políticas, sociais, culturais e ambientais, em diferentes escalas. Essas atividades econômicas historicamente foram capazes de promover e estimular importantes transformações espaciais, reestruturando o espaço de muitas cidades e até mesmo regiões, e, gradativamente, constituindo espaços ou regiões de turismo e de estadia temporária, voltados para o lazer, o descanso, com belezas naturais e infraestrutura.

2 A "indústria dos lazeres", (como afirma Lefebvre, 2008), passa a valorizar e ressignificar os elementos do meio ambiente, que são adaptados e modelados, prontos para serem consumidos a nível global, considerados como uma "nova raridade" (expressão do mesmo autor). Os espaços produzidos por essa "nova indústria" são conteúdos de diversas 
propagandas, uma alternativa de expansão do mercado imobiliário, de uma rede de serviços e outras indústrias, como a de construção. É possível visualizar basicamente um modelo geral de cidade turística e de estadia temporária, que articula: [I] o fator ambiental (a praia, o mar, o calor; a serra e o frio; espaços verdes, cachoeira, lagos, entre outros), [II] a necessidade do descanso e lazer (construção que ganha forma com as propagandas), [III] a estratégia de expansão do mercado imobiliário e [IV] a construção de infraestrutura e transformações no processo de urbanização. (GEORGE, 1973; LEFEBVRE, 2008; DANTAS, 2009, 2010; PEREIRA,2014; SILVA, 2010; CALETRÍO, 2011;TULIK, 1992; entre outros.)

3 O conjunto de fatores que estão alicerçados o turismo e estadia temporária são similares, logo, muitas cidades turísticas são cidades de estadia temporária. Por conseguinte, há algumas distinções importantes entre as atividades: o turismo tem como produção espacial imediata a rede hoteleira, que é muitas vezes capaz de atender diferentes camadas da sociedade, do albergue até o hotel de extremo luxo, nem sempre as cidades turísticas recebem um fluxo contínuo, com o retorno dos mesmos grupos de turistas. Já a estadia temporária produz espacialmente as residências secundárias ou os domicílios de uso ocasional, que são residências localizadas em cidades diferentes da primeira residência, utilizadas nas férias, no verão, nos fins de semana prolongados e feriados pelos mesmos grupos, sendo o lugar do lazer e descanso, diferenciando-se da monotonia e da rotina intrínsecos à primeira residência (como trata Lefebvre, 2008), assim, as cidades de estadia temporárias apresentam um fluxo de certa forma contínuo de moradores temporários nesses períodos específicos.

4 Esse artigo se estabelece como resultado de pesquisas e ao mesmo tempo de novas reflexões, que estão concentradas na análise da reestruturação espacial e econômica das cidades turísticas e de estadia temporária, tendo como estudo de caso, a cidade de Cabo Frio, cidade do interior do estado do Rio de Janeiro, com cerca de 212 mil habitantes (segundo estimativa do IBGE para 2016ㄹ). Inserida na Região das Baixadas Litorâneas, com inúmeras belezas naturais, a cidade passa por uma série de investimentos, em diferentes escalas, até se consolidar enquanto capital da região turística e de estadia temporária.

Evidenciaremos, além dos processos econômicos e espaciais comumente tratados os limites do modelo de cidade turística e de estadia temporária implementado na cidade e os conflitos gerados por essas atividades econômicas, estabelecendo como parâmetro central de comparação a alta temporada, com o crescimento exponencial da economia e da população temporária, e, a iluminação dos hotéis e residências secundárias, por conta do fluxo de pessoas, e, em contrapartida, a baixa temporada, com a estagnação da economia, diminuição do contingente populacional e do consumo, e, consequentemente, da escuridão dos quartos de hotéis e das residências secundárias.

\section{A invenção de uma necessidade}

6 Há uma série de circunstâncias e processos que apontam para o crescimento vertiginoso do turismo e da estadia temporária enquanto atividades econômicas de referência, e, a proliferação de residências secundárias e rede hoteleira, enquanto evidências físicas desse processo, junto com um conjunto de transformações espaciais. Um ponto importante é a construção e invenção de uma nova necessidade, que é vital para a manutenção do sistema capitalista consumista, um processo que ocorre ininterruptamente, principalmente a partir do século XX. O turismo e a estadia temporária são também novas 
necessidades, consequentemente, é indispensável à construção do discurso ou imaginário e do aspecto material ou físico, das cidades turísticas e de estadia temporária. É possível ressaltar alguns elementos para a discussão:

7 [I] O retorno ou a busca pelos elementos do meio ambiente, a nova raridade, ausente ou restrito nos grandes centros urbanos, acinzentados, poluídos e construído, considerados como uma antítese do meio ambiente. (GEORGE, 1973; LEFEBVRE, 2008; SANTOS, 2015) Os elementos do meio ambiente são adaptados, modelados, artificializados, e, compõe o espaço como atrativos, que obrigatoriamente devem conter uma infraestrutura para receber o turista e o morador temporário, além de ter qualidade para a permanência, como aponta George (1973), no tripé acesso, condições de permanência e qualidade da permanência. ${ }^{2} \mathrm{O}$ mesmo autor ainda afirma que o meio ambiente passa a ser uma mercadoria, o embelezamento do quadro urbano passa a ser objeto de novas produções e fonte de novos lucros (GEORGE, 1973); Carlos (2015), diretamente influenciada pelas análises de Lefebvre, afirma que na condição de raridade, a natureza transformou-se numa mercadoria nova. Smith (1988) afirma que em um novo contexto, há agentes que usufruem da natureza, destacando o controle político do Estado.

8 Faz-se mister ressaltar que o meio ambiente já se constitui como uma importante mercadoria para o sistema capitalista, concebido enquanto recurso natural, necessário para o lucro e expansão do sistema, o que de fato muda, principalmente no século XX, quando o sentido de mercadoria se amplia, transformando o meio ambiente também em algo a ser conservado, modelado, adaptado e produzido (como ressalta Smith, 1988), e, uma reserva para o uso do capital. (CARLOS, 2015; RAMAO, 2015 b)

9 [II] A busca por uma anestesia temporária da rotina estressante e de grande carga horária de trabalho, por um momento de descanso e de lazer, amalgamado ao sonho de passar as férias no litoral, ou um feriado em uma área de montanha ou serra, o charme e glamour de cidades, os serviços de alta qualidade de hotéis, uma residência secundária de frente para o mar, entre outros exemplos, que mostram além de uma cidade que virou mercadoria e está à venda, há uma valorização dos atrativos ambientais ligados a uma infraestrutura, colocados em um contexto de consumo. As fotos, os banners, os sites, os comerciais, os vídeos e o discurso dos promotores imobiliários constroem imagens dos espaços a venda, e, de como os turistas e moradores temporários poderiam usufruir desses espaços, concomitantemente, da necessidade de buscar esses espaços no contexto caótico do cotidiano, sendo melhor, por exemplo, para o casal que trabalha incessantemente, um lazer para os filhos, enfim, cria-se uma fantasia em nome do lucro.

10 Para o turismo, muitas vezes a distância entre o espaço emissor de turista e o receptor pode não ser relevante ou determinante, contudo, para o morador temporário é fundamental que a residência secundária se situe a uma distância confortável para a locomoção até a uma nova cidade e para o retorno a cidade da primeira residência. Abordando sobre esse processo nos Estados Unidos, George afirma:

Existem nas proximidades das cidades - incorporadas à megalópole - com espaços reservados aos piqueniques à sombra, com mesas e bancos de madeira, em regiões litorâneas acessíveis, a algumas horas de carro, ou nas "regiões selvagens" do oeste, para onde vão caravanas durante o verão. (...) (GEORGE, 1990, p. 106)

Espaços são fabricados exatamente para atender o turista e o morador temporário que busca o descanso e a tranquilidade; os próprios elementos do meio ambiente citados são combinados a um ritmo mais lento de um grande centro urbano; as regiões selvagens, como descreve George, são domesticadas e adaptadas para o conforto dos usuários; e as 
caravanas atuais são visíveis muitas vezes nos feriados, nas férias e alta temporada, quando uma multidão de automóveis se desloca de um centro urbano para o interior e/ou litoral, quando os aeroportos ficam lotados e até mesmo as rodoviárias precisam aumentar significativamente o número de ônibus, já que o turismo, por exemplo, não se restringe as camadas mais abastadas da sociedade, mesmo que o poder financeiro seja um diferencial.

Nesse caso, o capital financeiro, associado ao capital industrial (o setor de construção civil) e buscando atender a uma nova demanda da economia - o crescimento de setor de serviços -, precisa da aliança dos empreendedores imobiliários com o poder municipal para se desenvolver, garantindo a gestão da metrópole dentro dos padrões necessários à reprodução continuada do capital.

(CARLOS, 2015, p. 56)

[III] A estratégia de expansão do mercado imobiliário para novos espaços, e por consequência expansão da indústria de construção e de inúmeros serviços, e a ação do poder público, encarando as cidades pequenas, médias, ou bordas da metrópole (nesse contexto), com uma vantagem competitiva em relação aos espaços da metrópole e de grandes centros urbanos (valor do espaço, dos impostos, disponibilidade de espaço para construir, valor da mão de obra, "atrativos ambientais", entre outros), segundo Carlos (2015, p. 55) "o espaço se torna raro no centro e suas vizinhanças, fenômeno que se materializa na escassez de terrenos (...)". No contexto do Brasil, essa expansão econômico-espacial é combinada à valorização dos espaços do litoral, de cidades pequenas até as capitais, e, como salienta Dantas (2009), com mudanças urbanas significativas, e, com a articulação com o poder público.

\subsection{0 turismo e a estadia temporária em Cabo Frio}

Mapa 1: Estado do Rio de Janeiro - Domicílios de Uso Ocasional (2010) [modificado], com destaque para Cabo Frio.

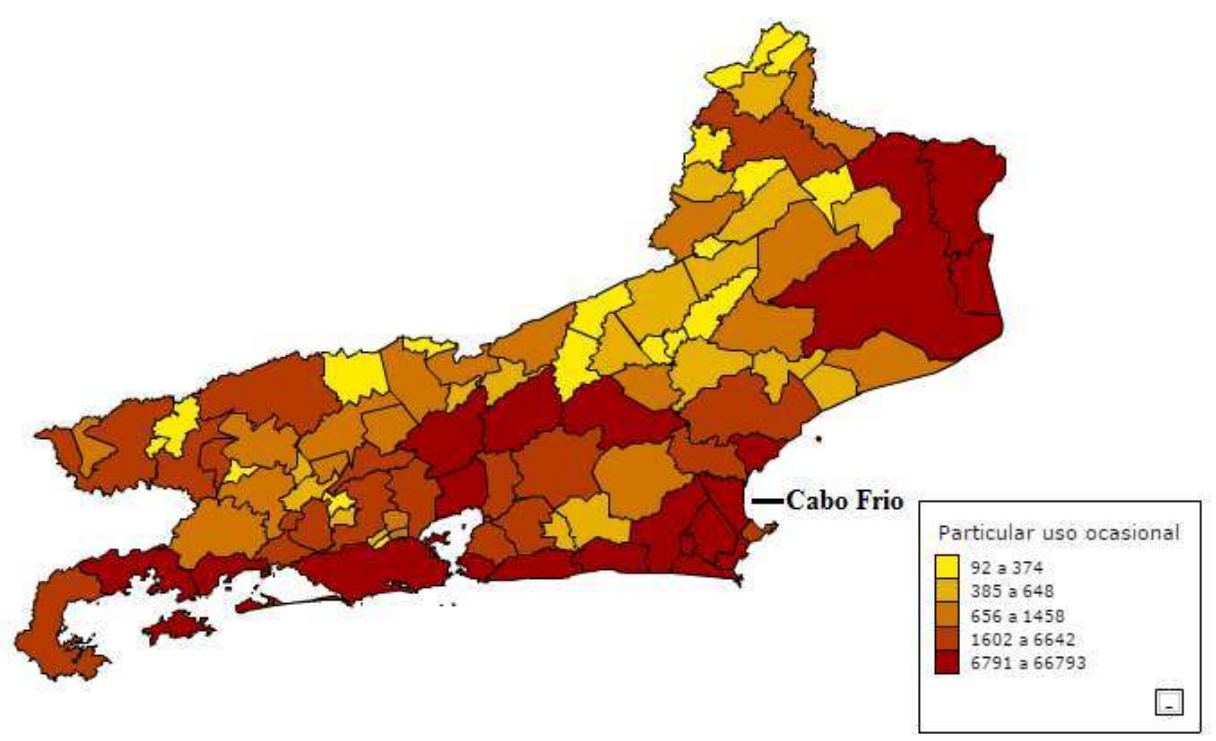

Fonte: censo2010.ibge.gov.br (adaptado). Acesso em 10 de abril de 2017

13 Cabo Frio é uma cidade do interior do estado do Rio de Janeiro, historicamente ligada com a atividade pesqueira, e, a partir do século XIX, também com a atividade salineira, que tem fases de crescimento e crise no município, assim como em toda região. A economia da 
pesca e do sal refletia diretamente no espaço, com bairros de pescadores, barcos e a cultura da pesca artesanal presente em vários pontos das cidades, o uso da laguna de Araruama (que atravessa os municípios da região) enquanto um espaço vital para o crescimento econômico e para a subsistência; e em relação à indústria salineira, com as grandes salinas, a ligação também com a laguna de Araruama de onde se extraia o sal, e, com fábricas para a industrialização do sal.

o desenvolvimento do turismo e da estadia temporária em Cabo Frio na segunda metade do século XX, pode ser compreendido na seguinte sequência :

a- A partir da década de 1940, temos políticas do governo do estado para a Região dos Lagos, compreendida já como uma região com potencialidade turística, com o Plano Diretor Amaral Peixoto

b- Nas décadas de 1950 e 1960, o surgimento e fortalecimento de órgãos municipais vinculados ao turismo na cidade de Cabo Frio. c- Na década de 1950 temos também a criação do bairro [loteamento] OGIVA em Cabo Frio, em uma grande área verde, próximo à lagoa, construído por um grupo de empresários do Rio de Janeiro. resultando em um bairro voltado para as residências secundárias, predominantemente de proprietários da cidade do Rio de Janeiro.

d- Ainda na década de 1950, a construção de Clubes Náuticos filiais (sub-sedes) ou de grupos do Rio de Janeiro, como o Iate Clube do Rio de Janeiro em Cabo Frio, e, uma década mais tarde o Clube Costa Azul Iate Clube, construído por grupos do Rio de Janeiro, para o lazer e descanso de grupos mais abastados da metrópole carioca.

e- Na década de 1960, o processo de urbanização de Cabo Frio se alonga até a praia do Forte, o que será um fator fundamental nas décadas seguintes, para a concentração da urbanização nas proximidades da praia.

20 f- Na década de 1970 e 1980, temos a melhoria da infraestrutura, principalmente em Cabo Frio, na orla da praia do Forte, com a presença maior de hotéis, como o hotel Malibu (de grande representação regional), reservado para turistas com alto poder aquisitivo; e, dos condomínios de luxo (Moringa e Moringuinha e Marinas do Canal), conduzidos por um grupo de empresários do Rio de Janeiro, liderados por Cesar Thedim.

21 g-Crescimento exponencial do fluxo de turistas de Rio de Janeiro, Minas Gerais, entre outros; a partir de 1997, uma nova rodada de transformações espaciais a partir de uma sucessão de governos de um mesmo grupo político, financiadas pelo dinheiro dos royalties do petróleo, que tem um crescimento astronômico com a Lei do Petróleo desse mesmo ano; reforma e melhoria na ligação entre o Rio de Janeiro e Cabo Frio com a Via Lagos, rodovia que foi privatizada. (RAMÃO, 2016).

A sequência temporal acima apresenta o processo de reestruturação econômica e espacial da cidade de Cabo Frio, que tornou-se uma cidade do turismo e da estadia temporária, superando as atividades da pesca artesanal e de sal. Essa passagem é gradativa e conturbada, pois passa pelo enfraquecimento da indústria salineira, que irá disputar com o sal do Rio Grande do Norte, e, terá menos investimentos de governos municipais - que deixam de ser vinculados a essa atividade, e, passam a investir no turismo e estadia temporária; e estadual ${ }^{3}$ - que investe na potencialidade regional para o turismo desde a década de 1940 (BAPTISTA 2007); com a poluição da laguna de Araruama; e, pela disputa espacial ou territorial, já que áreas de salinas serão tomadas pelo mercado imobiliário, dando origem a bairros e condomínios, junto a espaços próximos a laguna e a praia, que 
serão igualmente de interesse do mercado imobiliário e serão espaços de conflito com a pesca.

A cidade de Cabo Frio irá reproduzir a tendência brasileira, de cidades litorâneas, ricas em belezas naturais, e, com uma infraestrutura básica e crescente, (mesmo com muitos problemas), tornando-se uma cidade turística e de estadia temporária, tendo um grande fluxo de população temporária em determinados contextos. Além disso, Cabo Frio se torna um importante refúgio, espaço de lazer e descanso para a população da cidade do Rio de Janeiro, evidenciando a relação existente entre metrópole e cidade pequena ou média do mesmo estado, no caso específico, essa relação é com toda Região dos Lagos ${ }^{4}$, assim como a cidade de São Paulo possui forte ligação com as cidades do litoral do mesmo estado. A rede hoteleira e os condomínios destinados majoritariamente à segunda moradia irão dominar muitos espaços nessas cidades, controlando principalmente as orlas das principais praias, lagoas e áreas verdes.

A partir do ano 2000, as cifras dos royalties do petróleo irão aumentar ainda mais, o embelezamento do quadro urbano pelo poder público municipal será mais intenso e concentrado no primeiro distrito, principalmente na orla da Praia do Forte e bairros próximos, a quantidade de turistas e empreendimentos de diferentes origens também atingirá números impressionantes. Junto à rede hoteleira e a construção de residências secundárias, que já se relacionam com outras indústrias e serviços para existirem, há uma pluralidade de serviços que estão apoiados e articulados com essas atividades econômicas na cidade de Cabo Frio ${ }^{5}$, como: os restaurantes, passeios de barcos, lojas de moda praia com destaque para o Gamboa Shopping (antiga rua dos biquínis), espaços de lazer como a Praça das Águas, Boulevart Canal (com restaurantes e casas de show), a orla da Praia do Forte (com restaurantes e bares), quiosques nas principais praias, Praça da cidadania (antiga Feira de artesanatos), e, um pouco mais distante do centro, o Shopping do Peró (conjunto de galerias), com restaurantes e bares, etc.

No Censo de $2010^{6}$, Cabo Frio se torna a sexta cidade no Brasil com o maior número de domicílios de uso ocasional no Brasil e segunda cidade no estado do Rio de Janeiro, contabilizando 34.719 domicílios desse tipo de uso, que podem ser igualados ao sentido de residência secundária, utilizada para o lazer e descanso na alta temporada, feriados prolongados e fins de semanas, e, ainda, com 10.766 domicílios vagos, em um total de 105.375 domicílios totais. (IBGE, 2010)

\subsection{Conflitos enquanto a luz está acesa e apagada}

Na orla da Praia do Forte, com maior pujança, mas também em outras partes da cidade, o efeito da presença de turistas e moradores temporários se torna visível com: as luzes dos prédios acesas, o movimento de pessoas nas ruas, nas praias, nos mercados, restaurantes, e, em todos os espaços de lazer citados, e o grande fluxo de pessoas na estrada que liga o Rio de Janeiro até a Região das Baixadas Litorâneas, principalmente a partir dos dados divulgados pela empresa da Via Lagos. ${ }^{7}$ 


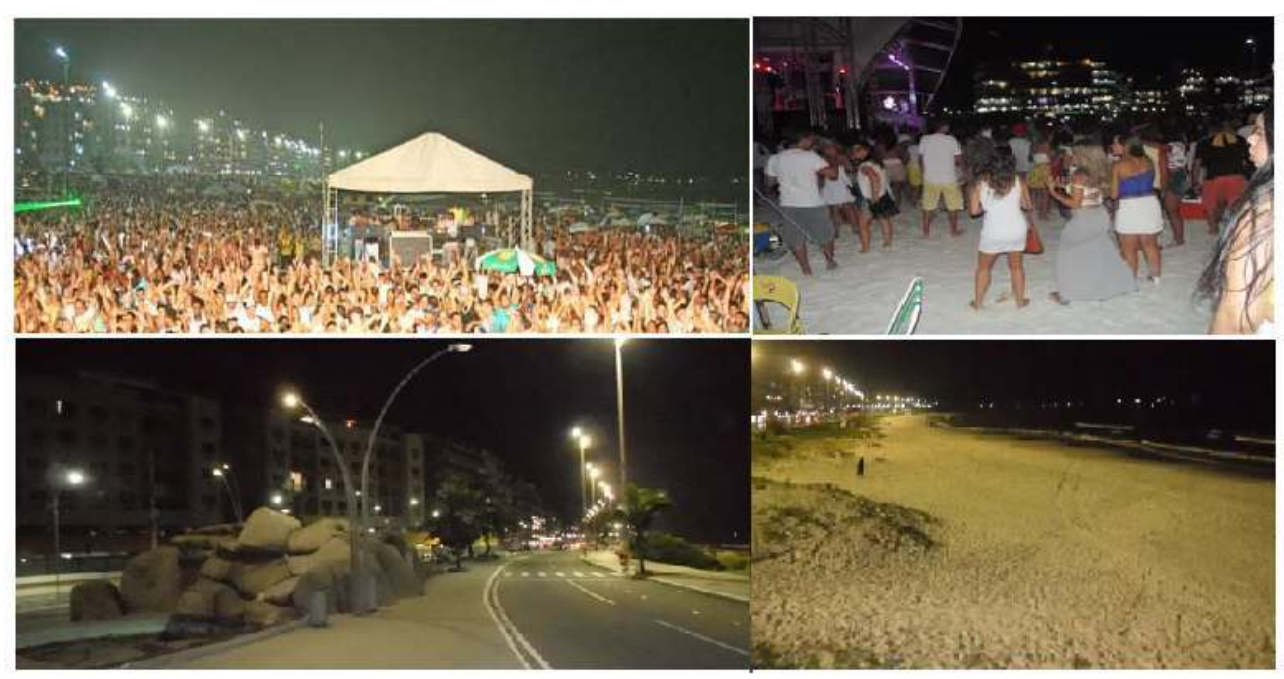

Fonte: Na parte superior: (à esquerda) Réveillon de 2009 - Jornal O popular da Costa do Sol www.bigpop.com.br/ Acesso em 10/04/2017; (à direita) Réveillon 2017 - fonte: http://g1.globo.com/ rj/regiao-dos-lagos/noticia/2017/ acesso em 10/04/2017. Na parte inferior: dia 10 de junho de 2017, fotos do autor, 2017.

As fotos oferecem a dimensão da mudança do espaço, que é drástica quando se compara a alta temporada e a baixa temporada na cidade de Cabo Frio, característica de um modelo de turismo e estadia temporária que privilegiam a praia, o sol e o calor, e, uma parte do ano (o verão), com o acréscimo de feriados prolongados e férias, e, consequentemente, produz uma dependência da economia local desses períodos, influenciando no trabalho e no lucro das empresas relacionadas a essas atividades. Além da limitação econômica, ligada à questão do trabalho, o modelo de cidade turística e de estadia temporária de Cabo Frio apresenta outros limites e conflitos que serão explorados a seguir:

\section{[1] Remoções, privatização e elitização do espaço.}

Para a orla da Praia do Forte se transformar em aparentemente um grande paredão de prédios luxuosos iluminados a noite na alta temporada, será preciso remover grupos pobres, muitos ligados à pesca e ao comércio na praia. Segundo Maricato (2015, p. 58): “A especulação corre solta, auxiliada por políticas públicas que identificam valorização imobiliária com progresso". A autora ainda complementa, que se aceita pobres em áreas de risco, em áreas de preservação, contudo, não se tolera pobres em áreas valorizadas pelo mercado imobiliário. (MARICATO, 2015)

29 No Jornal O Globo de 1978, a remoção da favela do Lido, chamada também como Favela da Barra, que fica na orla da Praia da Forte, é destaque, na matéria: Cabo Frio remove favela na Praia da Barra. Cerca de 400 pessoas moravam naquele momento na favela, e, foram removidas para bairros novos, localizados depois da ponte (O GLOBO, 1978 apud RAMÃO, 2015), que se consolidava enquanto um marco de divisão das áreas mais desenvolvidas da cidade (antes da ponte) e os bairros periféricos da cidade (depois da ponte), com algumas exceções. Os moradores localizados na orla da praia ganhavam terrenos da prefeitura na área periférica da cidade, a cerca de $8 \mathrm{~km}$ de distância da praia, e, tinham barracos e bares (como tratado na reportagem) demolidos, contudo, naquele momento, muitos moradores já reclamavam pela distância do trabalho com as novas casas.

30 Parte da população da favela do Lido resistiu, crescendo nas décadas posteriores, e existentes até hoje, assim como outra favela próxima, a Buraco do Boi, que atualmente se 
restringe a poucas ruas. Ambas estão praticamente "escondidas" na orla da praia e muitas tentativas de remoção aconteceram no decorrer das décadas, sob o comando de diferentes prefeitos, inclusive, atacando as formas de sustento dessa população, com o enfraquecimento da pesca e o abandono, com a retirada dos quiosques de madeira da praia onde parte da população da favela do Lido trabalhava, com a regulamentação e restrição do trabalho de ambulantes.

O nível de privatização destas áreas ainda é bastante elevado. Cerca de $60 \%$ das margens já urbanizadas na primeira e segunda seção do canal são de domínio privado. Ainda assim, parte das áreas aterradas que estão disponíveis ao livre acesso público, como o Boulevard Canal, próximo ao centro da cidade, constituemse em 'territórios de turistas', onde a paisagem do canal é subjetivamente apropriada como pano de fundo para o consumo turístico em restaurantes, bares e boates situados às suas margens, inibindo sua apropriação por parte da população local e visitante não-consumidora destes serviços. A paisagem inicialmente 'vendida' pelo capital imobiliário passou a ser comercializada de forma mais evidente pelo capital turístico. (MELO, 2011, p. 18)

31 A população temporária no verão além de ocupar as residências, muitas vezes, próximas a laguna e próximo ao mar, a áreas verdes, e no decorrer das orlas das praias, principalmente da Praia do Forte, tem aumentado a população de Cabo Frio, pelo menos a partir da década de 1950, três, quatro ou até cinco vezes. Como indicado, a quantidade de empregos temporários gerados no período de alta temporada é significativo ${ }^{8}$, contudo, na baixa temporada, a oferta de emprego diminui drasticamente, tendo pequenas oscilações em feriados prolongados, onde por exemplo restaurantes, bares e casas de show contratam funcionários para dias específicos.

\section{[II] A limitação da infraestrutura}

32 A década de 1970 significa o aumento considerável do fluxo de turistas para a cidade de Cabo Frio, consequência do marketing feito desde a década anterior, o surgimento de novos projetos imobiliários e depois de 1974, a diminuição do percurso entre Rio de Janeiro e Cabo Frio, por conta da construção da ponte Rio - Niterói. Isso significa o aumento da renda da cidade em uma determinada época do ano, mas também terá impactos significativos no serviços básicos da cidade, como a água, a luz, a saúde pública, mercados, e, no meio ambiente, com a ocupação e construção em novas áreas. A figura abaixo demonstra o crescimento do fluxo de pessoas na cidade em paralelo ao crescimento dos problemas gerados pela falta de infraestrutura da cidade.

Figura 2: Falta de infraestrutura em Cabo Frio em 1970

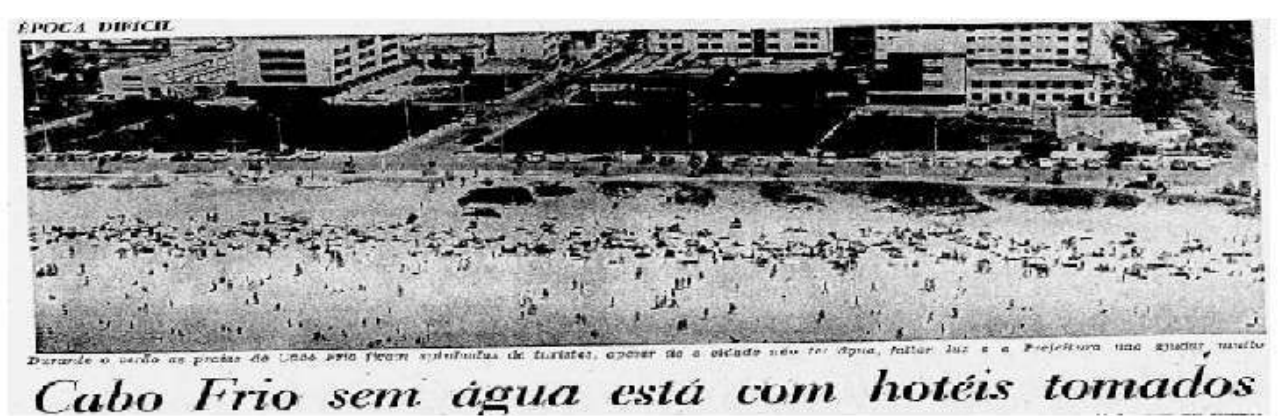

Fonte: Jornal do Brasil, 1970 
Os problemas se repetem e se ampliam no fim da década de 1970 e continuarão nas décadas seguintes, com menos intensidade para luz e água na atualidade, mas com grande pujança para os serviços de saúde, para os mercados, tratamento de esgoto, produção de lixo, etc.

A reportagem do jornal o Globo de janeiro de 1978, ressalta que "Cabo Frio espera 400 mil turistas este mês", mostrando que a rede hoteleira já estava saturada, mas existia a possibilidade dos turistas de alugarem casas. 0 mais interessante é que $o$ valor variava entre $\mathrm{Cr} \$ 20$ a $\mathrm{Cr} \$ 50$ mil por mês, e, próximo ao Canal Itajuru (lagoa) as residências alcançavam o valor de $\mathrm{Cr} \$ 100$ mil, o que mostra não só a qualidade das residências próximas à lagoa, mas o preço adicional incluído pela proximidade com esse elemento do meio ambiente. Outra preocupação nesse momento é o abastecimento de água, pois segundo o prefeito desse momento José Bonifácio, “o abastecimento de água estava normal, mas ele esperava que a CEDAE cumprisse o que tinha prometido - não deixar a cidade sem água durante o verão". (O GLOBO, 1978) Um ano mais tarde, Cabo Frio ficaria sem água por 15 dias, fazendo com que o mesmo prefeito recorresse mais uma vez ao governador do estado, esperando medidas emergenciais, e, assim, hospitais e hotéis dependiam de carros-pipa. (RAMÃo, 2015, p. 111)

\section{[III] Os impactos ambientais}

34 Na cidade de Cabo Frio, pelo menos nos últimos 30 anos ficaram visíveis: os impactos no campo de dunas, diminuindo abruptamente por conta do processo de urbanização e retirada da areia para fins comerciais; a poluição da laguna de Araruama que chega até a cidade e a própria poluição gerada na cidade; o desmatamento de áreas verdes, também por conta do processo de urbanização; o crescimento da produção de lixo e esgoto principalmente na alta temporada, entre outros impactos que afetarão áreas de restinga, manguezais e áreas verdes. ${ }^{9}$

Moura (2005), ao tratar da área do Parque Municipal Dormitório das Garças, identifica uma série de impactos no manguezal gerado principalmente pelo uso de comunidades do entorno do parque e ainda pela poluição da laguna de Araruama. Bertucci et al.(2016) , relaciona o crescimento demográfico acelerado desde a década de 1970, a falta de estrutura das cidades da região, incluindo Cabo Frio, com a poluição da laguna de Araruama.

O crescimento demográfico desordenado ${ }^{10}$ às margens da lagoa - a partir dos anos 1950 e, principalmente, após a inauguração da ponte Rio-Niterói, em 1974, e da melhoria das rodovias de acesso (RJ-104, 106) - determinou um aumento da pressão antrópica sobre o ecossistema, pondo em risco a sua saúde (LIMA-GREEN, 2008; MELO, 2011). A ocupação ocorreu de forma caótica, sem a devida fiscalização das prefeituras e o aporte de água doce proveniente das águas de uso da população, o que causou uma mudança de estado no sistema que tem consequências até hoje (MOREIRA-TURCQ, 2000). O contínuo lançamento de esgoto in natura na lagoa provocou mudanças significativas em seu equilíbrio ambiental. $O$ aumento da concentração de nutrientes, especialmente fósforo e nitrogênio, ocasionou o processo conhecido como eutrofização cultural. (BERTUCCI et al, 2016, p. 49)

\section{[IV] A violência}

Em duas reportagens do Jornal o Globo de 1979, a violência na cidade de Cabo Frio é um tema relevante, com assaltos principalmente a lojas e hotéis da cidade, gerando muita instabilidade entre a população, turistas e moradores temporários. Os comerciantes reagem a partir de um grande protesto com as lojas fechadas e 700 comerciantes em uma 
manifestação, reivindicando um maior policiamento na cidade e mais segurança. (O GLOBO, 1979 apud RAMÃO, 2015) No decorrer das décadas a violência cresce ainda mais, inclusive com a consolidação de facções criminosas na cidade, territorializando alguns bairros, tendo relação direta com o crescimento dos recentes números de homicídios na cidade, alcançando o primeiro lugar no mapa de violência no estado do Rio de Janeiro com dados entre 2010 e 2012 e a única cidade do estado a constar no ranking dos 100 municípios brasileiros com mais mortes por arma de fogo. (WAISELFISZ, 2013)

\section{Considerações finais}

O turismo e a estadia temporária são importantes atividades econômicas no mundo atual, responsáveis pelo crescimento econômico de muitas cidades e capazes de provocar um processo de reestruturação espacial e econômica, articulado a fatores políticos, com consequências no meio ambiente, na sociedade e cultura. Cabo Frio é um grande exemplo desse processo, sendo a capital do turismo e de estadia temporária de toda a Região das Baixadas Litorâneas, cidade onde o processo econômico e espacial é mais agudo, e, onde as consequências de todas essas transformações se manifestam com maior pujança.

Há características comuns que aproximam as cidades turísticas e de estadia temporária em todo o mundo. No Brasil a exploração do litoral é fundamental para o crescimento exponencial dessas atividades econômicas, capitaneadas pela ação do Estado, em suas diferentes esferas, e a ação do mercado imobiliário, de diferentes origens. Mais do que identificar e analisar os aspectos econômicos e políticos, que são assaz relevantes, é preciso compreender questões sociais que estão presentes nas cidades turísticas e de estadia temporária, já que em muitos casos, a atmosfera de festa, a celebração e lazer, junto, ao city marketing, escamoteiam uma série de conflitos e limites do modelo dessas cidades, e, de fato, referente a todos os aspectos, a questão espacial está inclusa.

o modelo de cidade turística e de estadia temporária de Cabo Frio, (e que pode ser estendido a outras cidades), está centrado no embelezamento do quadro urbano, e, secundarizou ou ignorou historicamente investimentos que poderiam melhorar a qualidade de vida da população, logo, o reflexo direto é que grande parte das transformações do espaço urbano está a serviço da acumulação do capital, com o domínio do mercado imobiliário e um Estado que age de acordo com a lógica de uma cidade para o turista, enriquecendo grandes empresas. Assim, o morador pobre localizado em áreas de interesse imobiliário, é frequentemente expulso ou sofre uma intensa pressão; paga pelo alto custo de vida nesse modelo de cidade; sobrevive de empregos temporários, já que a oferta de emprego tem uma grande oscilação entre a alta temporada e a baixa temporada; é afetado pelo aumento da violência e pela especulação imobiliária.

As luzes acesas nas residências secundárias e nos quartos de hotéis durante a alta temporada e períodos específicos do ano, e, apagadas no período de baixa temporada, são sintomas de uma cidade que sobrevive de forma desigual, e, é completamente dependente da luminosidade da economia do turismo e de estadia temporária, ao mesmo tempo, que exprime sua deficiência em comportar historicamente esse grande fluxo de pessoas, mesmo que em um período curto. Além disso, Cabo Frio vive o paradoxo da expansão do mercado imobiliário, da construção e da população nas últimas décadas, degradando o meio ambiente em larga escala, concomitante a permanente necessidade de explorar, 
conservar e vender os elementos do meio ambiente, como forma de atração de turistas e moradores temporários.

Desde 2013, com a diminuição da receita dos royalties do petróleo, uma desastrosa gestão municipal, a cidade passa por um momento de estagnação econômica, agravado ainda mais pela crise econômica que afeta o país, onde o setor de turismo e da estadia temporária é atingido, o que novamente irá evidenciar a fragilidade da economia local, do modelo de cidade turística e de estadia temporária, que pode ser estendido à realidade de muitas cidades brasileiras.

\section{BIBLIOGRAFIA}

ACSELRAD, H. (org) A duração das cidades - sustentabilidade e risco nas políticas urbanas. Rio de Janeiro, DP\&A, 2001.

ALVES, M. R. da Silva. Conjunto paisagístico de Cabo Frio. In: XII SIMPURB, Belo Horizonte, MG, 2011.

BAPTISTA, José Correia. A longa marcha - A dominação política da oposição em Cabo Frio após o Golpe de 1964. Cabo Frio: Ed. Jornal de Sábado, 2007.

BERTUCCI, T. C. P. et al. Turismo e Urbanização: Os problemas ambientais da Lagoa de Araruama - Rio de Janeiro. Ambiente \& Sociedade, São Paulo, nº 4, out - dez, 2016.

BRASIL. Instituto Brasileiro de Geografia e Estatística. IBGE. Censo demográfico de 2010.

CALETRÍO, JAVIER. "De veraneo en la playa”: pertencimento e o familiar no turismo de massa no Mediterrâneo. Est. Hist., Rio de Janeiro, vol. 24, nº 47, p. 119-140, janeiro-junho de 2011.

CHRISTÓVÃO, J. H. de O. Do sal ao sol: a construção social da imagem do turismo em Cabo Frio. 2011. Dissertação (Mestrado) - Faculdade de Formação de Professores, Universidade do Estado do Rio de Janeiro, São Gonçalo, 2011.

DANTAS, E. W. C. et al. Turismo e imobiliário nas metrópoles. Rio de Janeiro, Letra capital, 2010. Maritimidade nos trópicos: por uma geografia do litoral. Fortaleza: Edições UFC, 2009.

GEORGE, Pierre. O Meio Ambiente. São Paulo: Difusão Européia do livro, Saber Atual, 1973 . Geografia dos Estados Unidos. Campinas: Papirus, 1990. Geografia Urbana. São Paulo, DIFEL - Difusão Europeia do livro, 1983.

HARVEY, D. A Produção Capitalista do Espaço. São Paulo: Editora Annablume, 2005.

INSTITUTO BRASILEIRO DE GEOGRAFIA E ESTATÍSTICA (IBGE). Censo 2010.Disponível em: censo2010.ibge.gov.br/ Acesso em 10 de abril de 2017. IBGE cidades - Disponível em: <https://cidades.ibge.gov.br/v4/brasil/rj/cabo-frio/ panorama> . Acesso em 10 de abril de 2017.

LAMEGO, A. R. O homem e a restinga - Rio de Janeiro. Edição fac-similar . Rio de Janeiro: IBGE, 2007 [1946]. 
LEFEBVRE, H. O direito à cidade. 4. ed. São Paulo: Centauro, 2006.

Espaço e Política. Editora UFMG, 2008.

MARICATO, E. Para entender a Crise Urbana. 1º edição - Expressão Popular, São Paulo, 2015.

MELO, E. S. O. de. Gênese da urbanização turística em Cabo Frio (1950 - 1978). XIV Encontro Nacional da ANPUR. Rio de Janeiro, 2011.

MOURA, J. H. M. Estratégias para a conservação e manejo do Parque Municipal Ecológico Dormitório das Garças, Cabo Frio, RJ. 2005. Dissertação (Mestrado) - Universidade Federal Fluminense, Niteroi, 2005.

OLIVEIRA, Floriano José Godinho de. Mudanças no espaço metropolitano: novas centralidades e dinâmicas espaciais na metrópole fluminense I. In: SILVA, CatiaAntoniada; FREIRE, Désirée Guichard; OLIVEIRA, Floriano José Godinho de (Orgs.). "Metrópole: Governo, Sociedade e Território". Rio de Janeiro: FAPERJ, DP\&A Editora, 2006.

OLIVEIRA, Leandro D. Seropédica sustentável: Uma análise sobre a reestruturação econômicoecológico-espacial da cidade. In. XIV SIMPURB, Fortaleza, 2015. Fortaleza, UFC, 2015. Anais, Fortaleza, Disponível em: http://simpurb2015.com.br/anais-2015/

OLIVEIRA, L. D. de; RIBEIRO, G. Notas Teórico-Metodológicas sobre o ordenamento territorial: Um ensaio político a partir das experiências de Volta Redonda e Cabo Frio. Rio de Janeiro, Tamoios, Ano V. n. 1, 2010.

As Territorialidades da Metrópole no Século XXI: Tensões entre o Tradicional e o Moderno na Cidade de Cabo Frio-REJ. Geo, 2007, v. 3, p. 108-127, 2009.

PEREIRA, A. Q. A urbanização vai à praia: vilegiatura marítima e metrópole no Nordeste do Brasil. Fortaleza, UFC, 2014.

RAMÃO, Felipe de Souza. A mercantilização do meio ambiente na cidade de Cabo Frio a partir dos fundamentos de Pierre George. 2015, 171 f. Dissertação (Mestrado em Geografia) - UERJ FFP, São Gonçalo, 2015ª.

Meio Ambiente, Espaço Urbano e Política a partir das contribuições de Pierre George: Um estudo de caso sobre a cidade de Cabo Frio, RJ. Fortaleza, UFC, 2015b. Anais, Fortaleza, Disponível em: http://simpurb2015.com.br/anais-2015.

REES W. E. Understanding urban ecosystems: an ecological economics perspective. In Understanding urban ecosystems, A Berkowitz, CH Nilon, and KS Hollweb (eds.) Springer, New York, 2003

RIBEIRO, Miguel Ângelo. Turismo no estado do Rio de Janeiro: ensaio de uma tipologia.IN:Revista GEOgraphia, ano V- n.10. Ed. Impressão entrelinhas, Rio deJaneiro,2003.

SANCHEZ,Fernanda. A (in)sustentabilidade das cidades-vitrine. In: ACSELRAD, Henri. A duração das cidades - sustentabilidade e risco nas políticas urbanas. Rio de Janeiro, DP\&A, 2001.

SANTOS, Milton. A Natureza do Espaço. 4. ed. São Paulo: EDUSP, 2008.

SILVA, Kelson de Oliveira. A residência secundária e o uso do espaço público no litoral oriental potiguar. 2010, 187 f. Dissertação (Mestrado em Geografia) UFRN - Universidade Federal do Rio Grande do Norte, 2010.

SMITH, N. Desenvolvimento Desigual. Rio de Janeiro: Bertrand Brasil, 1988.

SOJA, E. Para além de Postmetropolis. Revista UFMG, belo horizonte, v. 20, n.1, 2013. 
TULIK, O. Turismo e meio ambiente: identificação e possibilidades da oferta alternativa. Revista Turismo em Análise USP v. 3, n. 1, 1992.

O turismo e os meios de hospedagens: casas de temporada. São Paulo, Roca, 2001.

WAISELFISZ, J. J. Mapa da violência 2013: mortes matadas por arma de fogo. CEBELA; 2013.

\section{NOTAS}

1. Disponível em: https://cidades.ibge.gov.br. Acesso em 10 de abril de 2017.

2. Nesse sentido, será fundamental o acesso até as cidades, o que muitas vezes significa a ligação entre regiões metropolitanas com bordas dessa região e cidades de menor porte, e, ainda, uma infraestrutura capaz de atender o turista, para esse permanecer, oferecendo também qualidade na sua permanência. $O$ "produto" cidade se torna mais caro a partir de "uma série de serviços, de cenários, que o irão transformar num ambiente fabricado, fonte de enormes operações de organização de regiões de turismo de verão e de inverno". (GEORGE, 1973, p. 90 - 91)

3. George (1973) aponta a grande função do fator político no processo de mercantilização dos elementos do meio ambiente, relacionados diretamente com o surgimento de cidades turísticas. Dantas (2010) relaciona o crescimento do turismo e as drásticas transformações urbanas de cidades do Nordeste por conta do PRODETUR - NE (Programa de Desenvolvimento do turismo no Nordeste).

4. 0 que se comprova com a análise do Mapa 1, onde toda a Região dos Lagos, inserida na Região das Baixadas Litorâneas, aparece com destaque em relação aos números de domicílios de uso ocasional.

5. A lógica de articulação das atividades econômicas com a indústria e uma pluralidade de serviços é uma característica que se estende as outras cidades turísticas e de estadia temporária.

6. No estado do Rio de Janeiro, a cidade do Rio de Janeiro apresenta maior número de domicílios de uso ocasional, quase 67 mil DUOs; em segundo, Cabo Frio, próximo aos 35 mil DUOs, posteriormente, Araruama (18.550), Maricá (17.558), Mangaratiba, 17.199, reforçando a relevância econômica do turismo e estadia temporária no estado do Rio de Janeiro, mais uma vez, visível no mapa 1.

7. Via Lagos é a empresa privada responsável pela administração da rodovia Lagos, principal ligação entre a Região das Baixadas Litorâneas ou na denominação turística e histórica Região dos Lagos, e, a região metropolitana do Rio de Janeiro. A Via Lagos produz estimativas ou informa a quantidade de fluxos de automóveis para a região em feriados prolongados e períodos de verão, réveillon, etc. Apenas para efeito de comparação, no feriado de novembro de 2016, entre os dias 11 e 14 , o fluxo de carros estimado para a região era cerca de 20 mil em cada dia, já o fluxo de carros para a região nos dias próximos ao réveillon era cerca de 40 mil por dia. Fonte: http:// www.rodoviadoslagos.com.br Acesso: 9 de abril de 2017.

Figura 1: Praia do Forte - Cabo Frio, na alta temporada e na baixa temporada.

8. A dependência da alta temporada e de fins de semana prolongados além da instabilidade econômica para o município, e, para os trabalhadores, gera novos ritmos no cotidiano para a população, como o trânsito com engarrafamentos, a precarização de serviços (desde serviços básicos como a saúde, até mercados e lojas) e o aumento do custo de vida.

9. Construção de casas, hotéis e do shopping Park Lagos em áreas de interesse ambiental, descumprindo, muitas vezes, a legislação ambiental.

10. Apenas a ressalva que o crescimento urbano e demográfico de Cabo Frio acontece de forma acelerada, a partir da segunda metade do século XX, contudo a aparentemente desorganização é a exata organização do sistema capitalista, que privilegiou grupos abastados locais e de várias 
origens, que ocuparam os espaços mais valorizados, enquanto a população de baixa renda foi gradativamente sendo deslocada para áreas longe do centro da cidade, e, dos espaços turísticos e de residência secundária.

\section{RESUMOS}

O turismo e a estadia temporária são atividades econômicas importantes e diretamente articuladas ao poder público e ao mercado imobiliário. Elas produzem a mercantilização dos elementos do meio ambiente, a ocupação e domínio do litoral brasileiro e o processo de reestruturação urbana de muitas cidades. A cidade de Cabo Frio (interior do Rio de Janeiro) transforma-se em uma cidade de turismo e estadia temporária a partir da segunda metade do século $\mathrm{XX}$, contudo, o modelo de cidade turística e de estadia temporária produzido na cidade apresenta limites e conflitos.

Tourism and lodging are important economic activities directly related to the government and the real estate market, which cause commodification of the environment, occupation and domain of the Brazilian coast as well as the urban restructuring process in many Brazilian coastal cities. Cabo Frio (Rio de Janeiro state) becomes a town oriented to tourism and lodging from the 1950s, however, the tourist town and lodging model adopted have limitations and conflicts attached to them.

El turismo y el alojamiento de temporada son actividades importantes, directamente articuladas al poder público y al mercado inmobiliario, lo que produce la mercantilización del medio ambiente y la ocupación y dominio del territorio, este es el proceso de reestructuración urbana de muchas de ciudades del litoral brasilero. Por su parte, la ciudad de Cabo Frío (interior del estado de Rio de Janeiro) se transformó en una ciudad turística a partir de la segunda mitad del siglo XX, modelo que actualmente presenta límites y contradicciones.

Le tourisme et les séjours temporaires sont des activités économiques importantes, en articulation directe avec les pouvoirs publics et le marché immobilier, engendrent une mercantilisation des éléments constitutifs de l'environnement, une occupation et une appropriation du littoral brésilien et un processus de restructuration urbaine dans bien des villes du littoral brésilien. La ville de Cabo Frio (État de Rio de Janeiro) est devenue une ville tournée vers l'accueil des touristes, qui y font des séjours temporaires, dans la seconde moitié du XXe siècle. Toutefois, ce modèle de ville touristique présente des limites et engendre des conflits.

\section{ÍNDICE}

Palabras claves: turismo, alojamiento de temporada, espacio.

Palavras-chave: Turismo, Estadia Temporária, Espaço.

Keywords: Tourism, Lodging, Space

Mots-clés: Tourisme, séjour temporaire, espace. 


\section{AUTOR}

\section{FELIPE DE SOUZA RAMÃO}

Doutorando no Programa de Políticas Públicas e Formação Humana (PPFH) - UERJ, Rio de Janeiro. Mestre em Geografia, UERJ - São Gonçalo, RJ. Membro do NUPEE- Núcleo de Pesquisa Espaço e Economia e do LAPEHGE- Laboratório Política, Epistemologia e História da Geografia, UFRRJ Seropédica, RJ. Email: feliperamao@yahoo.com.br 